Die Zeit des Sehens und der Raum des Hörens 
This page intentionally left blank 
Albert Breier

\title{
Die Zeit des Sehens \\ und \\ der Raum des Hörens
}

\author{
Ein Versuch \\ über chinesische Malerei \\ und europäische Musik
}

Verlag J. B. Metzler

Stuttgart - Weimar 
Die Deutsche Bibliothek - CIP-Einheitsaufnahme

\author{
Breier, Albert: \\ Die Zeit des Sehens und der Raum des Hörens : Ein Versuch \\ über chinesische Malerei und europäische Musik/Albert Breier \\ - Stuttgart ; Weimar : Metzler, 2002 \\ (M-\&-P-Schriftenreihe für Wissenschaft und Forschung) \\ ISBN 978-3-476-45266-5 \\ ISBN 978-3-476-02777-1 (eBook) \\ DOI 10.1007/978-3-476-02777-1
}

Dieses Werk einschließlich aller seiner Teile ist urheberrechtlich

geschützt. Jede Verwertung außerhalb der engen Grenzen des

Urheberrechtsgesetzes ist ohne Zustimmung des Verlages unzulässig und

strafbar. Das gilt insbesondere für Vervielfältigungen, Übersetzungen,

Mikroverfilmungen und die Einspeicherung

und Verarbeitung in elektronischen Systemen.

M \& P Schriftenreihe für Wissenschaft und Forschung

(C) 2002 Springer-Verlag GmbH Deutschland

Ursprünglich erschienen bei J.B. Metzlersche Verlagsbuchhandlung

und Carl Ernst Poeschel Verlag GmbH in Stuttgart 2002 


\section{Inhaltsverzeichnis}

\section{Leitsätze 1}

\section{Einleitung 7}

\section{Teil I}

\section{Die Musikalität der chinesischen Malerei}

\section{1 Raum und Zeit in Musik und Malerei}

\section{Auge, Ohr und Intellekt 27}

Sehsinn und Realität - Hörsinn und Deutung - Bewegung und Zeitlichkeit - Alltag und Kunst

\section{Der imaginäre Raum der Musik 30}

Ausschaltung des äußeren Raums in der Musik - Gerichtetheit der Zeit - Form Partitur - Melodie und Kontrapunkt

\section{Über den Kanon 34}

Der raumschaffende Intellekt - Rationalismus und räumliche Extension - Aufzeichnung der Kanons - Entstehung von Harmonik und Tonalität

\section{Raum und Zeit in der bildenden Kunst. Europa und China 38}

Verflüchtigung des Raums in der europäischen bildenden Kunst - Zentralperspektive - Verschwinden auch der Zeit - Zeit in der chinesischen Malerei - Wandelperspektive - Bildformate - Zusammenhang der Zeitdarstellung mit der chinesischen Geisteswelt

\section{Ein Bild von Xiang Shengmo 45}

Beschreibung des Bildes - Bewegungsarten - Mathematik - Wasser - Gleichgewicht - Pinselstriche - Kosmos, Jahreszeiten 


\section{Das Philosophische der Künste 52}

Zeit und Raum bei den chinesischen Philosophen - Begrifflichkeit und Räumlichkeit in Europa - Philosophische Kraft von Malerei und Musik - Daoismus

\section{Individuum und Bewegung 58}

Portrait - Kalligraphische Bewegung - Tanz und Polyphonie - Kompositorische Individualität bei Mozart und Beethoven - Individuum und Konvention - Negativität des Individuellen - Tanz und Kalligraphie - Individuelle Bewegungsarten

\section{Die Linie und das Universum 66}

Die Linie als Ursprung der Malerei - Handgelenk und Seele - Ockeghem, die bewegliche Linienführung in der Musik - Das Gesetz der menschlichen Stimme - Die Spuren des Künstlers im Bild - Ungetrenntheit von Künstler, Bild, Betrachter und Universum - Unwirkliches und Wirkliches - Distanz und Bewegung des Betrachters

\section{2 Entsprechungen in künstlerischen Darstellungsweisen und ästhetischen Kategorien}

\section{Das Melodische 73}

Das Melodische als Essenz der Musik - Entsprechungen zwischen Melodiebehandlung und Malweise - Notation; Linie und Punkt - Chinesische Linienmelodien

\section{Chaos und Gestalt 77}

Das Urchaos in der Musik (Beethoven) - Fang Congyi's Bild Berge in Wolken "Chaos" in China - Klarheit und Ungreifbarkeit der Musik - Abstraktion in der europäischen Kunst

\section{Erinnerung - Wiederholung - Reprise 82}

Rolle der Wiederholung in der europäischen Musik - Der erinnernde Rückblick Kontrast - Kampf der Prinzipien - Andeutung von Ähnlichkeiten in der chinesischen Malerei - Die Kunst der Erinnerung - Morton Feldman

\section{Das Detail und das Ganze 86}

Durchformung des Kunstwerks - Problematische Details - Der Künstler als Diktator - Dong Qichang - Titel chinesischer Bilder 


\section{Das Symphonische 89}

Das symphonische Paradigma - Die Symphonie als Welt - Die chinesische Malerei des 10. und 11. Jahrhunderts - Fan Kuan's Bild Reisende zwischen Strömen und Bergen - Beethoven und Wagner - Die Musik der europäischen Romantik und die Malerei der Südlichen Song-Zeit - Guo Xi - Das „Überbild” - Renaissancen des Symphonischen

\section{Die Grenzen des Erfaßbaren (1) 98}

Überfülle der Details - Gustav Mahler - Arnold Schönberg - Das Lesetempo der chinesischen Malerei - Kuncan - Orchestrierung - Natur bei Kuncan und Mahler

\section{Ökonomie der Mittel 103}

Ökonomie und Abstraktion - Andeutungen - Kammersymphonie - Anton Weberns Variationen op. 30 - Ni Zan und sein Bild Das Rongxi-Studio - Innerer Reichtum Die Kunst in schwierigen Zeiten

\section{Die Grenzen des Erfaßbaren (2) 110}

Teilnahme der Phantasie - Ni Zan's Umgang mit der Leere - Leere als grundlegendes Prinzip - Pausen in der europäischen Musik - Stille bei Webern - Faßlichkeit „Geistes-Resonanz"

\section{3 Zur geistigen Welt der chinesischen Malerei}

\section{Über das Rätsel 115}

Verschiedene Auffassungen des Rätselhaften - Nutzlos gelöste Rätsel - Giorgione Rätselkanons - Adornos „Rätselcharakter der Kunst” - Europäische und chinesische Kriminalromane - Balance des Erklärlichen und des Unerklärlichen - Mathematische Geheimnisse - Dürers Melencolia I - Rätsel und Bewegung

\section{Ein Gedicht von Li Shangyin 120}

Die bunte Zither - Schriftzeichen und Pinselstriche - Vieldeutigkeit - Das Ganze des Kunstwerks - Definiertheit der musikalischen Motive - Verwandtschaft von Dichtung und Malerei in China - Das integrale Kunstwerk 


\section{Das Üben 126}

Darstellung der Wahrheit und Übung - Trennung von Komponist und Interpret Malfehler - „Zuverlässigkeit” der chinesischen Malerei - Illusionismus und Abstraktion in der europäischen Malerei - Kunstkritik - Skizzen - Vervollständigen von

Fragmenten durch Andere - Malerei als öffentliche Vorführung - Übung und Erleuchtung

\section{Über Anwesenheit 133}

Selbstportraits - Pinselführung - Der baimiao-Stil - Photographie - Die „Wendung”

\section{Über den Gesprächscharakter der Kunstwerke 135}

Der Gesprächspartner - Vertraulichkeit und Distanz - Diskretion - Die Rolle des Rezipienten - Gesprächscharakter der Musik - Das universale Gespräch - Parallelismus - Unterhaltung des Raums mit der Zeit

\section{Das Licht; Sonne und Mond 141}

Gleichmäßiges Tageslicht - Atmosphärisches in der chinesischen Malerei - Der wandelbare Mond - Mondbetrachtung - Spiegelungen - Musik und Dunkelheit Lichtregie in der europäischen Malerei - Zentral-Licht

\section{Der Klang des Baumes 146}

\section{Über den Wald 148}

Waldsymbolik der abendländischen Architektur - Das Orchester als Klang des Waldes - Wald und Mathematik - Darstellung der Baumblätter - Der alte Baum

\section{Über den Wasserfall 151}

\section{Rose und Lotos 152}

\section{Kindheit 154}

Das Erwachen am Morgen - Prophetische Kinderreime - Blinzeln - Malversuche von Kindern - China als Land des Anfangs - Nacht und Licht in der abendländischen Musik (1) - Verlust des Kindlichen - Chromatik - Das Erotisch-Musikalische - Der starre Blick - Das Schließen der Augen 


\section{Über das Schwarze 159}

Die europäische und die chinesische Trauerfarbe - Metaphern der Farbigkeit in der chinesischen Malerei - Gong Xian's Bild Tausend Gipfel und Myriaden Schluchten Nacht und Licht in der abendländischen Musik (2) - Die "schwarze Tonart" Verschwinden der Farbigkeit in der europäischen Malerei - Schwarz als Farbe - Der abstrakte Expressionismus - Der „blanke” neue Mensch Mao's - Die „schwarzen” chinesischen Maler des 20. Jahrhunderts - Das Graue - Die schwarze Sonne

\section{Über den Traum der roten Kammer 167}

Traumwelt und Wirklichkeit - Malerei und Roman - Gartenkunst - Roman und Musik - Vorahnung der Katastrophe - Ende des Alten China - Aufklärung und Albtraum

\section{Über die chinesische Musik 171}

Unbekanntheit der chinesischen Musik - Die Qin - Stille - Musik und Sitte - Musik und Religion - Der Einzelton - Fehlen der „Komposition” in der chinesischen Musik - Musik und Freude - Trauer in der europäischen Musik - Vergänglichkeit - Musik und Bild - „Inneres Lauschen” 


\section{Teil II}

\section{Der Weg des Klangs}

\section{II.1 Sprache und Schrift}

\section{Über die chinesische Schrift 183}

Sprache und Schrift - Das chinesische Schriftzeichen - Schrift und Philosophie Verehrung der Schrift - Ordnungsdenken in Malerei und Schrift - Unheimlichkeit der Schrift - Lesbarkeit der Bilder

\section{Über die chinesische Kalligraphie 195}

Kalligraphie als Beherrscherin der Künste - Schönheit - Kunstcharakter der Kalligraphie - Malerei und Kalligraphie - Kalligraphie als Ausdruck der eigenwilligen Persönlichkeit

\section{Über das Yijing 207}

Das Denken des Auges - Einheit von Sprache und Mathematik - Das Yijing als Orakelbuch - Shao Yang und Leibniz - Das moderne westliche Interesse am Yijing Vorläufigkeit der Vollendung

\section{Klang und Bedeutung 213}

Sprachlaut und Gedanke - Gehör und Systemdenken - Mißtrauen gegen den Laut Vernehmen des Logos - Sein und Klang - Philosophie als Stimmengewirr - Buchstabenschrift - Notenschrift - Esoterische Lyrik - Mallarmé und die Musik - Linguistik - Phonozentrismus - Verschwinden des Lautes $h$ - Die Antinomie der Sprache Linguistik und Wissenschaft - Schuld der Sprache

\section{Über das Sprechen im 20. Jahrhundert 241}

Trennung von Buchstaben- und Bilderschrift - Ornament - Hindurchgehen der Sprache durch die Schrift - Fachsprachen - „Information” - Flüchtigkeit des gesprochenen Worts - Lüge - Kampf gegen die ostasiatischen Schriftzeichen - Redewendungen - Film - „Algebraisierung” der Schrift - Verlust des Ohrs, Verlust des Auges - Wortlosigkeit

\section{Lesen 258}

Schrift und Buch - Der lesende Körper - Partiturlesen - Das Lesen und die Nacht Lesen und Gespräch - Unlesbarkeit - Schrift und Gerechtigkeit 


\section{Joyce 267}

Der Roman als Kunstform - Unübersetzbarkeit des joyceschen Werks - Das Buch als Welt

\section{Musik und Sprache 271}

Trennung von Wort und Ton - Geschichtliches - Rationale Musik - Deutschland als Land der Musik und die deutsche Sprache - Unverständlichkeit der Musik - Sprache und Wahnsinn - Die Sprache der Natur

\section{II.2 Die Künste im Zusammenhang der Kultur}

\section{Mathematik 282}

Musik als Zweig der Mathematik - Mathematik des Tonraums - Sprache und Mathematik - Geschichte und Mathematik - Verschwinden der Mathematik aus der Musik Das chinesische Zahlenverständnis - Stimmungssysteme - Notenschrift Kontrapunkt

\section{Rhythmus 292}

Rhythmus und Zeit - Rhythmus in der chinesischen Kunst und Literatur - Rhythmus und Metrum - Akzent - Sprechtöne im Chinesischen - Dreiteiligkeit - Lebendiger und erstarrter Rhythmus - Stockhausens Rhythmustheorien

\section{Geschichte 303}

Die Rhythmen der Geschichte - Das Geschichtliche der Kunst - Formen und Tendenzen - Historismus - Musik und Musikgeschichte - Todverfallenheit - Umkehrbarkeit der Zeit - Zyklische Geschichtsauffassung - Kunstgeschichte und Persönlichkeit Ennui und „Fadheit”

\section{Ockeghem 314}

„Chinesen" in der europäischen Kultur - Versagen der Musikwissenschaft - Freiheit des Komponierten - Ockeghem und der Kontrapunkt - Notenschrift als Inspirationsquelle - Modalität - Ockeghem und die Musikgeschichte - „Vox aurea”

\section{Symmetrie 320}

Symmetrie und Notenschrift - Symmetrische Formen und Figuren in der Musik - Dur und Moll - Klavier und Computer - Griechische Architektur - Symmetrie des menschlichen Körpers - Blakes „fearful symmetry” - Chinesische Malerei als Kunst der Asymmetrie - Philosophie der Asymmetrie - Unmöglichkeit der Symmetrie 


\section{Natur 327}

Willkür und Ordnung - „Naturgesetze” - Rameau und Rousseau (1) - Natur und Physik - Chinesische Landschaftsbilder als Teil der Natur - Gartenkunst

\section{Ferne 336}

Fernwirkungen in der europäischen Musik - Der „ferne Klang”- Musik aus der Ferne gehört - Ferne in der chinesischen Malerei - Räumliche und zeitliche Ferne - Die Farben der Ferne - Vernichtung der Ferne

\section{Kultur 346}

Der Kulturbegriff Spenglers - Einheitliche Entwicklung der Menschheit - Reisners Kulturverständnis - Kultur und Religion - Kulturordnung in China - Kultur und Zivilisation - Kulturfeindschaft - Charakteristik und Verhältnis der Hochkulturen Gegensatz China-Westen - Alleinherrschaft Europas - Die „Eine Welt” - Stockhausens „Weltmusik” - Herrschaft des Intellekts - Universalwissenschaft - „Polyphonie des Wissens" - Mandelstams Begriff der Weltkultur

\section{Klassik 367}

Das Klassische und die Musik - Die Wiener Klassik - Klassizismus - Klassische Literatur - China und das Klassische - Die Malerei der Song-Zeit - Vermeiden des Klassischen

\section{Absolute Musik 374 \\ Mehrstimmigkeit und Instrumentalmusik - Nichtigkeit, Form - Christlich-Musikali- sches und Antik-Plastisches - Rameau und Rousseau (2) - Geräusch - Punktförmig- keit - Gesetz und Freiheit - Subjektbegriff - Kunstreligion - Sieg der ratio}

\section{Dissonanz 382}

Physis, Psyche und Intellekt - Dissonanz und System - Der Tritonus - Die dissonante Musik des 20. Jahrhunderts - Unterhaltungsmusik - Harmonische Indifferenz - Die kleine Sekunde - Cluster - Einzigartigkeit der Dissonanz als Erscheinung in der Kunst - Paradieswelt der chinesischen Malerei

\section{Nietzsche 389}

Musikalische Philosophie - Nietzsche und Wagner - Musikalische Logik - Zustürzen auf die Katastrophe - Finalität - „Logik des Zusammenbruchs” - Die Stimme des Philosophen - Musik und Lüge - Nietzsche und Zhuang Zhou - Christentum und Nihilismus - Die „Kultur des Filioque” - Christliche Kultur 


\section{II.3 Ende und Zukunft von Malerei und Musik}

Die Katastrophe der europäischen Musik 401

Endlichkeit der Musik - Zusammenbruch der Tonalität - Zusammenbruch des musikalischen Raumes - Ersatzkonstruktionen - Stockhausen und die Phänomenalisierung des Raums - Geschwindigkeit - Der Tonpunkt - Cage und die Phänomenalisierung der Zeit - Tod und Allgegenwärtigkeit der Musik - Musikbetrieb - Musik und Weltende

Komponieren heute 429

Bewußte Erfahrung der Katastrophe - Musik und Apokalypse - Schubert und die Trauer - Morton Feldman - Die neue Musik und die Neue Musik - Konkrete Musik Platz der Musik in einer zukünftigen Kultur - Heilwirkung der chinesischen Malerei Verhältnis der Europäer zur chinesischen Malerei

Die chinesische Malerei im 20. Jahrhundert 446

Tod der chinesischen Malerei - Verschwinden der Landschaft - Ende des Alten China - Archäologie - Huang Binhong - Rückblick auf die chinesische Malerei

Über Raum-Zeit und Schönheit 453

Verkehrung von Raum und Zeit in der Kunst - Untrennbarkeit von Raum und Zeit Bedingung der Schönheit

\section{Teil III}

Eine Bildlektüre im Sinne der symphonischen Musik: Xiang Shengmo, Ein unbedrängter Unsterblicher, frei von Fesseln, mitten unter rauschenden Kiefern

Vorbemerkung 459

Bildlektüre 463

Auswahlbibliographie 513 